\title{
Analysis of ante mortem trauma in three modern skeletal populations
}

\author{
M. STEYN ${ }^{1}$, M.Y. İSSCAN ${ }^{2}$, M. DE KOCK ${ }^{1}$, E.F. KRANIOTI ${ }^{3}$, M. \\ MICHALODIMITRAKIS ${ }^{3}$ AND E.N. L'ABBé ${ }^{1}$ \\ ${ }^{1}$ Department of Anatomy, University of Pretoria. \\ ${ }^{2}$ Adli Tip Enstitisu, University of Istanbul, \\ ${ }^{3}$ Department of Forensic Sciences, Medical School, University of Crete, 71110, \\ Heraklion, Greece.
}

Corresponding author: Prof M Steyn, Department of Anatomy, P.O. Box 2034, Pretoria

0001, South Africa.

E-mail: maryna.steyn@up.ac.za

Tel: 27-12-4203256 Fax: 27-12-3192240 


\section{ABSTRACT}

When archaeological skeletons are assessed, the incidences of trauma are important. The number of fractures observed is interpreted in order to gain insight into the occurrence of interpersonal violence, workload, living conditions, etc. However, the question remains as to how these results should be interpreted - i.e., what constitutes high or low levels of trauma. The aim of this study was to investigate the occurrence of trauma in a population of modern Greeks living on Crete, as well as South African (SA) whites and blacks in the Pretoria Bone and Raymond Dart collections. The sample comprises mostly of older individuals ( $\mathrm{n}=90$ - 100 of each sex- population group). Each skeleton was studied for healed trauma. For the vertebrae only spondylolysis was assessed. In Greeks it was found that $42 \%$ of the males and $46 \%$ of females had at least one fracture, with corresponding figures of $63 \%$ and $44 \%$ for SA whites and $83 \%$ and $69 \%$ for SA blacks. Radius, rib and femur fractures were most common in Greeks, with skull, radius and ribs most common in SA whites and skull, ulna and ribs in SA blacks. These incidences of trauma are high, but the composition of the samples (mostly of lower socio-economic origin) should be kept in mind. It may also be questioned whether these individuals reflect the society as a whole. It seems that the fractures in Greeks are mostly related to old age due to falls and accidents (e.g., Colles and hip), while the SA black sample reflects high incidences of interpersonal violence (e.g., cranial vault and parry fractures). The SA white sample follows an in between pattern. These comparative figures may be useful when assessing trauma in other skeletal populations.

Key words: Greek; South African black; South African white; spondylolysis; cranial fractures; osteoporosis; lifestyle; Colles fracture 


\section{Introduction}

Signs of injuries sustained during life are often preserved in the human skeleton after death. These traumatic lesions include healed and perimortem fractures, separation of cranial sutures, spondylolysis, dislocations, subluxations, avulsions and amputations DiMaio \& DiMaio, 2001). The assessment of trauma is an integral part during an investigating of skeletal remains, be they of archaeological or forensic origin. In archaeological contexts, especially, the frequencies of various fractures are often used to gain information on the lifestyle and culture of the people represented by the remains (e.g., Grauer \& Roberts, 1996; Stirland, 1996; Judd, 2004; Brickley, 2006; Torres-Rouff \& Costa Junqueira 2006; Van der Merwe et al n.d.).

Trauma and fractures in populations can result from violent or accidental encounters with animals, other people or cultural hazards found at home or work (Merbs, 1989; Lovell, 1997; Neri \& Lancellotti, 2004). They can also be the result of therapeutic procedures, and bone may fracture due to an underlying disease such as malignancy or osteoporosis. The location, prevalence, shape, appearance, multiplicity, sequence and severity of trauma are influenced by intrinsic factors such as age and sex, as well as external factors such as culture and living conditions (Glencross \& Stuart-Macadam, 2000; Lovell, 1997; Ortner, 2003 ; Spitz, 2006).

These factors all contribute to expose individuals to specific traumatic hazards during life. Therefore, the study of the prevalence and patterns of healed trauma within a population can help to reconstruct their occupational and environmental stresses. It can also give information as to their cultural behaviour, such as the level of medical care available, technology used (e.g., for transport, agricultural equipment), while cranial, 
forearm and rib fractures may indicate interpersonal violence within the population (Steinbock, 1976; Smith 1996; Jurmain \& Bellifemine, 1997; Kilgore et al., 1997; Lovell, 1997; Standen \& Arriaza; Jurmain 2001; Ortner, 2003; Brickley 2006). Notwithstanding these limitations, the assessment of trauma within a population can still yield considerable information (Ortner, 2003).

The prevalence of trauma in a population is difficult to assess and interpret, for several reasons. Firstly, limitations exist when dry bone is analyzed as skeletons are often poorly preserved, and fragmentation or incompleteness of skeletal remains may obscure diagnoses. Post depositional damage may also mimic healed trauma (Grauer \& Roberts, 1996). In addition, injuries sustained during childhood may have been completely remodelled at the time of death, especially if they occurred very early in life.

Some of the studies in the past concentrated on cranial trauma (e.g., Jurmain \& Bellifemine1997; Torres-Rouff \& Costa Junqueira 2006), trauma to the ribs (e.g., Brickley 2006), fractures of the postcranial skeleton (Mays 2006; Neri \& Lancellotti 2004), and trauma on the skeleton as a whole (Grauer \& Roberts 1996; Stirland 1996; Whitting \& Zernicke 1998 ;Galloway 1999; Van der Merwe et al n.d.). Specific traumatic lesions linked to certain occupations have also been investigated (e.g., Gilgore et al 1997). In all of these cases, however, the matter of interpretation remains difficult. For example, what actually comprises a high incidence of cranial trauma? When is the frequency of parry fractures high enough to suggest high levels of interpersonal violence?

In order to interpret data on trauma frequencies in past populations, more information on the occurrence of traumatic lesions in populations with different historical and cultural backgrounds is needed. The purpose of this study was therefore to describe the 
occurrence of trauma in three modern skeletal populations from different areas of the world, from different socio-economic backgrounds. Notwithstanding several limitations such as the differences in mean age between the populations and the question of how much they actually represent the living population, data can be obtained that will assist in the interpretation of traumatic lesions from other areas in the world. For the purpose of this study, remains of modern Greeks living on Crete, South African blacks and South African whites were studied.

\section{Materials and methods}

For the purpose of this study, it was attempted to obtain 100 males and 100 females from each of the three populations under study. All skeletons used are of known individuals, with sex and ancestry recorded. Age was recorded for most, but not all individuals. A relatively unknown skeletal collection of about 220 skeletons are housed in Heraklion, Crete. The study population derives from two cemeteries in Heraklion and consists of individuals that were born between 1867 and 1956, and had died between 1968 and 1998, thus all individuals had lived in the $20^{\text {th }}$ century. Some of these remains had soft tissue on them, resulting in the fact that for this study, only 99 males and 100 females could be included. Most individuals were of the middle to lower socio-economic class, and it can be assumed that many conducted at least a fair amount of manual labor.

Four hundred skeletons of South Africans were used, which were obtained from the Pretoria Bone Collection at the Department of Anatomy, University of Pretoria (L’Abbé et al 2005) as well as from the Raymond Dart collection at the University of the Witwatersrand. The skeletons within these collections were attained form various donors 
and hospitals (individuals that are unclaimed by relatives) for medical dissection training, after which they were macerated and placed into the bone collection for further research. These remains mostly reflect people of lower socio-economic status, and all died of natural causes. The skeletons were randomly selected from the two collections, but an effort was made to ascertain that complete skeletons were used.

The age distribution of all individuals is shown in Table 1. As can be seen from this table, the majority of, but not all, ages were known. With the exception of the South African blacks, most individuals were of advanced age and it can be assumed that most of the females were post-menopausal. Even though some young individuals were included, for example 19-year old Greek and South African white females, the majority are older people with the highest mean age in the Greek female sample (72.0 years) and the youngest in the South African black female group (46 years). The standard deviations ranged between 12 and 17 years.

All skeletons were analyzed macroscopically for signs of healed trauma. No Xrays were taken. In each individual, a specific bone was scored as present or absent, and the presence of a fracture noted. Hand and foot bones as well as the sternum were excluded. For the vertebrae only spondylolysis was assessed, and for the crania only cranial vault fractures. Trauma to the crania also included healed sharp force trauma (e.g., Figure 1) and surgical procedures such as is seen in Figure 2, which would most probably have been performed for a subdural haematoma. Most other trauma comprised simply of healed/partially healed fractures. In the case of the ribs it was sometimes difficult to be certain of a fracture (Jurmain, 1999; Brickley, 2006), and a conservative approach of under- rather than over estimation was followed. A rib had to be more than $80 \%$ 
(estimated) complete to be included, otherwise it was noted as absent. Some of the individuals had prostheses such as hip replacements, which may have been due to chronic degeneration or trauma. As it was not possible to determine the cause of the prosthesis, they were scored as fractures.

Male-female differences in each population were statistically tested by means of an Equality of Proportions test (for a 2-sample case) for each bone. Thereafter, only the most commonly fractured bones such as the skull, radius, ulna, femur and ribs were further analyzed. For each population, the left and right sided bones were combined, and the total frequency in a population compared to that in each other population, also by means of an Equality of Proportions test.

\section{Results}

The frequencies of trauma to each bone are shown in Tables $2-4$ for each of the populations. It was found that in the Greeks, 42 (42\%) of the males and 47 (47\%) of females had at least one fracture. The difference between the males and females is not statistically significant ( $\mathrm{z}=-0.64769$; Equality of Proportions test). Of these, 23 (55\%) of males and 30 (64\%) of females had more than one fracture. The maximum number of fractures observed in a male was six, which included rib fractures, while the maximum number of fractures in a female was 10 (including rib fractures, found in two individuals). Multiple trauma was therefore common.

Cranial trauma was observed in one individual only, and no mandibles were affected (Table 2). Fractures of the proximal femur (6\% of all femora) and distal radius (Colles fractures, 6\% of all radii) were the most prevalent in the sample, with the females 
having been affected more than the males. Females had a larger number of fractures of the left radius ( $\mathrm{p}<0.05)$ and right femur $(\mathrm{p}<0.1)$, but when both sides were combined no significant differences between the occurrence of fractures between males and females was found.

Fractures of the ulna were not often recorded, but it is well known that Colle's fractures may occur without involvement of the ulna. One of the males and two of the females had bilateral radial fractures. Only one scapular fracture was noted, and fractures of the clavicles, tibiae and os coxae, although present, were also not common.

As far as rib fractures are concerned, $4 \%$ of all ribs studied in this population were fractured. This affected $29 \%$ of the 97 males who had ribs, and $31 \%$ of the 88 females with ribs. More than 3\% of all ribs observed were thus fractured, involving 28 of the males and 27 of the females. Taking into account that 127 fractured ribs were found, it is clear that several individuals had more than one rib fracture.

Spondylolysis of lumbar vertebrae were found in $1.4 \%$ of all lumbar vertebrae, and occurred more in males (although not significantly so).

In the South African white group, $61 \%$ of males and $41 \%$ of females had at least one fracture. The difference between the White males and females is statistically significant $(\mathrm{z}=2.828993 ; \mathrm{p}<0.01)$. Of the individuals with trauma, $43(70.5 \%)$ of the males had more than one fracture, and 27 (65.9\%) of the females. The maximum number of fractures in both males and females were 12. Individuals with multiple fractures usually had several healed rib fractures, which were very common $6.3 \%$ of left sided ribs and 4.6 of right sided ribs. 
Cranial fractures were fairly common, and occurred in $8.1 \%$ of males and $3.3 \%$ females, a total of 5.8\% (Table 3). Four individuals had mandibular trauma. Aside from the cranium and ribs, the most commonly fractured bone in females was the right radius (8.1\%) followed by the femur (5\% left, $4 \%$ right). In the white male population, the right clavicle was the most common long bone fractured (7.4\%) followed by the right radius (6.2\%).

Spondylolysis was rare, and only seen in the males. Three females had hip replacements and one female and one male a knee replacement. Four males had various other orthopedic devices (pins and metal plates) and another four had surgical trauma on their crania.

In the South African black group, $77 \%$ of the males and $69 \%$ of females had fractures ( $\mathrm{z}=1.274183$; not significant). More than one fracture occurred in $79.2 \%$ of the males who had fractures, and $69.6 \%$ of the females and the maximum number of fractures in a male was14, and in a female 11. Once again rib fractures were very common, occurring in 9.5\% of left ribs and 7.1\% of right ribs (Table 4).

Cranial fractures were frequently observed, and occurred in $15 \%$ of males and $20 \%$ of females (difference not statistically significant). In both males and females $2 \%$ of mandibles showed healed trauma. Aside from cranial and rib fractures, the most commonly involved bones in males were the left ulna (14\%) and left fibula (9\%), while in females both ulnae (left 14\% and right 12\%), the left radius (8\%) and fibulae (6-7\%) were most frequently broken. None of the individuals had spondylolysis. 
Only one black female had signs of surgical procedures (pins in a left radius), while four black males had screws and plates in various long bones, and only one black male had surgery on his cranium.

When the incidences of trauma between the three populations are compared (Table 5), some interesting patterns emerge. Cranial trauma is the most common in SA blacks (17\%), followed by the SA whites (6\%) and then the Cretans (0.5\%). Differences between all groups were statistically significant. The SA black group also has the most ulna (parry) fractures (11.2\%), with frequencies of just more than $1 \%$ in the other two groups. Rib fractures are also the most common in SA blacks (8.3\% of all ribs), followed by SA whites (5.5\%) and Cretans (3.7\%). Femur fractures are the most common in the older Cretes (6.4\%), followed by the SA whites (3.3\%) and SA blacks (1\%). Radial fractures are common in all populations, but are also most common in the Cretans (6.2\%), with similar frequencies of $4.6 \%$ in the other two groups. Clavicular fractures were fairly common in all groups, with scapular, humeral, tibial and os coxal fractures being the least common. Spondylolysis was rare, and did not occur in SA blacks at all.

\section{Discussion}

Interpretation of trauma frequencies is difficult, and the question of how much any skeletal population reflects its source population can rightly be asked (Komar \& Grivas, 2008). This is even more so in the case of individuals in a modern skeletal collection, which is a highly selected group and could most probably be regarded as mostly reflecting the lower socio-economic group. The age composition of the sample also plays a role, and in this case most probably also reflects something of the life 
expectancy of the group under study. Both the Greeks from Crete and the SA white samples comprise mostly older individuals and most of the females were probably postmenopausal. The SA black group died younger, and most probably reflects people who are at high risk as far as various diseases and traumatic incidents are concerned.

The prevelance of trauma reported here are surprisingly high for modern societies, with a frequency distribution between $41 \%$ and $77 \%$ for the various sex-population groups. L’Abbe \& Steyn (2007), for example, found that only 7\% of individuals in a modern Venda (African) sample had fractures. Judd (2004) reported trauma frequencies of $42-46 \%$ in archaeological specimens from Kerma, while Jurmain (2001) reported much lower incidences in prehistoric Californians. Kilgore et al (1997) reported long bone fractures in 33.5\% of Medieval Nubains, Standen \& Arriaza (2000) reported incidences of 30\% in a pre-historic Chilean population, while according to Stirland (1996) about one third of people in Medieval Norwich, had fractures. These comparisons are, however, difficult because these studies assessed different cultural and socioeconomic groups, as well as different types of fractures.

The high incidence of trauma in the Crete sample can probably be ascribed to the fact that the sample population was mostly of advanced age of often osteoporotic individuals, making falls and accidents more likely. This is reflected in the patterns of fractures, with many radius, femur head and rib fractures, and only one cranial fracture.

The younger South African black sample reflects a high incidence of intrapersonal violence, with many cranial and parry fractures. Many individuals also had rib fractures and fibula fractures. It is interesting to note that the highest incidence of cranial fractures is in the black female sample with $19 \%$ of individuals affected, which may also 
reflect domestic violence. The South Africa white sample follows an in-between pattern with many fractures that could possibly be associated with older individuals with osteoporosis (femur and radius), but also a relatively high number of individuals with cranial fractures. High incidences of right clavicular and lower leg fractures in the males may be associated with strenuous sports (e.g., rugby which is very popular among this group).

According to Black \& Cooper (2000), Colle’s fractures are the most frequent osteoporotic fractures in the first two or three decades after menopause, until old age (more than 75 years old), when femur fractures are more common. In this study the occurrence of fractures in these two bones is about even (both around 6\% of all femora and radii), probably reflecting the fact that many of the individuals in this sample were quite old. The mean age of the individuals with radius fractures was 83.6 for females (8 with known ages) and 63.75 for males (only 4 with known ages); in comparison with 75.9 for females (8 with known ages) and 68.8 for males (6 with known ages) for femur fractures. Thus in females radius fractures were more common in older ages, and in males femur fractures were more common in older people.

Although not necessarily statistically significant, both femur and radius fractures are more common in females in the two older samples (Crete and SA white). This most probably reflects the increased likelihood of females to suffer from osteoporosis, or other problems associated with age and bone degeneration.

According to Mays (2006) Colle’s fractures is fairly regularly noted in large skeletal series, with a crude prevalence of about $1 \%$ or less which is considerably less than what was found in this study. This is most probably due to the inherent 
characteristics of the study population. Apparently about 30\% of Colle’s fractures can lead to long term disabilities, which would have had a significant impact in the populations under study (O’Neill et al 2001).

In the study by Mays (2006) he commented that many of the Colle’s fractures observed in his British archaeological population would have been considered as malunited by modern standards; this was not the case in the populations studied here where healing seems to have been adequate. This is in contrast to what was found on the femoral fractures from Crete, with a surprising number of individuals with totally unhealed fractures (unfused femoral heads) and no attempt at surgical repair. Surgical repair was more common in the SA white sample. This finding correlates well with the war period of 1941-1945 against German occupation when almost all Cretans participated in a well organized resistance, as well as the civil war (1945-1950) right after the liberation of the island. Apparently it was not always possible in the majority of the local people to receive medical treatment under such circumstances. Another possible explanation could be the poor development of the public health system of Crete in the life time of these individuals belonging mainly to the lower socio-economic class. The national medical system in Greece started operating only in the last two or three decades. It can be assumed that the individuals suffered from severe impairment afterwards, and that great care was taken by relatives to look after the affected people such that they had survived for a long time after the injury so that healing (although not union) could take place.

In the well-known paper on the osteological paradox (Wood et al, 1992), the question was asked as to whether signs of disease (and thus also trauma) in a skeletal 
population actually reflects the hazards people were exposed to. The major issue here is that individuals who die with signs of disease (or maybe also of trauma) on their skeletons would have been those who had lived long enough to develop skeletal lesions. In the skeletons under study here, it is significant to note that the group with the highest incidence of trauma (the SA black group) also had the youngest mean age. This may indicate that the higher exposure to traumatic incidents may eventually also lead to an increased risk to die younger, but remains difficult to interpret.

In conclusion it seems that modern living poses several hazards, such that trauma frequencies are higher in the modern populations recorded here than in many archaeological populations. It seems that more than 50\% of people to survive into old age will have healed antemortem fractures. Trauma patterns related to old age and osteoporosis were found in the Crete sample. Both South African samples show very high incidences of trauma, much of which can be related to inter-personal violence. Rib fractures are non-specific, and occurred frequently in all populations. This may imply that it will be difficult to interpret the frequencies of rib fractures in archaeological populations.

\section{Acknowledgements}

M Steyn would like to thank the NRF and Department of Anatomy for the funding to conduct this study. We are grateful towards the University of the Witwatersrand for the use of the Raymond Dart Collection. M Steyn would also like to acknowledge the hospitality of the University of Crete during her stay on the island. 


\section{References}

Black DM, Cooper C. 2000. Epidemiology of fractures and assessment of fracture risk. Clinics in Laboratory Medicine 20:439-453.

Brickley M. 2006. Rib fractures in the archaeological record: A useful source of sociocultural information? International Journal of Osteoarchaeology 16:61-75.

DiMaio V, DiMaio D. Forensic Pathology, 2nd ed, CRC Press, Boca Raton, 2001, pp. 173-4.

Galloway, A. (Ed) 1999. Broken bones: Anthropological analysis of Blunt Force Trauma. Spigfield IL: Charles C Thomas.

Glencross B, Stuart-Macadam P. 2000. Childhood trauma in the archaeological record. International Journal of Osteoarchaeology 10: 198-209.

Grauer AL, Roberts CA. 1996. Paleoepidemiology, healing, and possible treatment of trauma in the medieval cemetery population of St. Helen-on-the -walls, York.England. American Journal of Physical Anthropology 100: 531-544.

Judd M. 2004. Trauma in the city of Kerma: Ancient versus modern injury patterns. International Journal of Osteoarchaeology 14: 34-51.

Jurmain R. 2001. Palaeoepidemiolgical patterns of trauma in a prehistoric population from central Calafornia. American Journal of Physical Anthropology 115: 13-23.

Jurmain R, Bellifemine VI. 1997. Patterns of cranial trauma in a prehistoric population from central California. International Journal of Osteoarchaeology 7: 43-50. 
Kilgore L, Jurmain R, Van Gerven D. 1997. Palaeoepidemiological patterns of trauma in a medieval Nubian skeletal population. International Journal of Osteoarchaeology 7: 103-114.

Komar DA, Grivas C. 2008. Manufactured populations: what do contemporary reference skeletal collections represent? A comparative study using the Maxwell Museum documented collection. American Journal of Physical Anthropology 137(2): 224-233.

Lovejoy CO, Heiple KG. 1981. The analysis of fractures in skeletal population with an example from the Libben site, Ottowa Count, Ohio. American Journal of Physical Anthropology 55: 529-541.

Lovell NC. 1997. Trauma analysis in paleopathology. Yearbook of Physical Anthropology 40: 139-170.

Mays SA. 2006. A palaeopathological study of Colle’s fracture. International Journal of Osteoarchaeology 16:415-428

Neri R, Lancellotti L. 2004. Fractures of the lower limbs and their secondary skeletal adaptations: a 20th century example of pre-modern healing. International Journal of Osteoarchaeology 14: 60-66.

O’Neill TW, Cooper C, Finn JD, Lunt M, Purdie D, Reid DM, Rowe R, Woolf AD, Wallace WA. 2001. Incidence of distal forearm fracture in British men and women. Osteoporosis International 12:555-558. 
Ortner DJ. 2003. Identification of pathological conditions in human skeletal remains, 2 edn. Amsterdam: Academic Press.

Smith MO. 1996. 'Parry' fractures and female-directed interpersonal violence: Implications from the later archaic period of west Tennessee. International Journal of Osteoarchaeology 6: 84-91.

Spitz W. 2006. Spitz and Fisher's Medicolegal Investigation of Death, $4^{\text {th }}$ Ed., Charles C Thomas, Springfield: 510-515.

Standen VG, Arriaza BT. 2000. Trauma in the pre-ceramic Coastal population of Northern Chile: Violence or occupational hazards? American Journal of Physical Anthropology 112: 239-249.

Steinbock RT. 1976. Paleopathological diagnosis and interpretation. Springfield: Charles C. Thomas publishers.

Stirland AJ. 1996. Patterns of trauma in a unique medieval Parish cemetery. International Journal of Osteoarchaeology 6: 92-100.

Torres-Rouff C, Costa Junqueira MA. 2006. Interpersonal violence in prehistoric San Pedro de Atacama, Chile: Behavioral implications of environmental stress. American Journal of Physical Anthropology 130: 60-70.

Wakely J. 1996. Limits to intepretation of skeletal trauma - Two case studies from medieval Abingdon, England. International Journal of Osteoarchaeology 6: 76-83. 
Whitting WC, Zernicke RF. 1998. Biomechanics on the Musculoskeletal Injury.

Champaign IL: Human Kinetics.

Wood JW, Milner GR, Harpending HC, Weiss KM. 1992. The osteological paradox problems of inferring prehistoric health from skeletal samples. Current Anthropology, 33(4): 343-370. 
Table 1: Sample sizes with age ranges and mean ages indicated. (n) is the total sample size, while the number of individuals with known ages are shown in parentheses

\begin{tabular}{lclll}
\hline Population & $\mathrm{n}$ & Age range & Mean age & SD \\
\hline Greek male & $99(62)$ & $34-94$ & 68.9 & 13.721 \\
Greek female & $100(60)$ & $19-100$ & 71.8 & 17.157 \\
South African white male & $100(93)$ & $28-94$ & 67.7 & 13.030 \\
South African white female & $100(98)$ & $19-94$ & 69.7 & 12.145 \\
South African black male & $100(100)$ & $16-96$ & 59.3 & 13.387 \\
South African black female & $100(99)$ & $20-82$ & 45.8 & 14.217 \\
& & & & \\
\hline
\end{tabular}


Table 2: Trauma frequencies in the Crete sample ( $\mathrm{n}=199)$. $\mathrm{Z}$-score refers to the Equality of Proportions test (for a 2-sample case) to test for significant differences between the sexes. $\mathrm{Npr}=$ number of bones that were assessed; $\mathrm{Naff}=$ number of bones with fractures

\begin{tabular}{lrrrrrrrrrc}
\hline Bone & \multicolumn{3}{c}{ Both sexes } & \multicolumn{3}{c}{ Males } & \multicolumn{3}{c}{ Females } & \multicolumn{2}{l}{ Z-score } \\
\hline & Npr & Naff & $\%$ & Npr & Naff & $\%$ & Npr & Naff & $\%$ & \\
\hline Skull & 199 & 1 & 0.5 & 99 & 1 & 1.0 & 100 & 0 & 0 & 0.992409 \\
Mandible & 197 & 0 & 0.0 & 98 & 0 & 0.0 & 99 & 0 & 0 & - \\
L Scapula & 192 & 1 & 0.5 & 97 & 1 & 1.0 & 95 & 0 & 0 & 0.997352 \\
R Scapula & 191 & 0 & 0.0 & 97 & 0 & 0.0 & 94 & 0 & 0 & - \\
L Clavicle & 180 & 1 & 0.6 & 95 & 1 & 1.1 & 85 & 0 & 0 & 0.984543 \\
R Clavicle & 185 & 2 & 1.1 & 95 & 1 & 1.1 & 90 & 1 & 1.1 & -0.03936 \\
L Humerus & 194 & 2 & 1.0 & 98 & 1 & 1.0 & 96 & 1 & 1.0 & -0.01466 \\
R Humerus & 194 & 7 & 3.6 & 96 & 3 & 3.1 & 98 & 4 & 4.1 & -0.35721 \\
L Radius & 194 & 11 & 5.7 & 97 & 2 & 2.1 & 97 & 9 & 9.3 & $-2.1731 *$ \\
R Radius & 191 & 13 & 6.8 & 96 & 7 & 7.3 & 95 & 6 & 6.3 & 0.269691 \\
L Ulna & 189 & 2 & 1.1 & 96 & 0 & 0.0 & 93 & 2 & 2.2 & -1.46329 \\
R Ulna & 190 & 3 & 1.6 & 96 & 2 & 2.1 & 94 & 1 & 1.1 & 0.569424 \\
L Femur & 194 & 13 & 6.7 & 97 & 4 & 4.1 & 97 & 9 & 9.3 & -1.43569 \\
R Femur & 197 & 12 & 6.1 & 98 & 3 & 3.1 & 99 & 9 & 9.1 & -1.75658 \\
L Tibia & 196 & 4 & 2.0 & 97 & 1 & 1.0 & 99 & 3 & 3.0 & -0.98484 \\
R Tibia & 197 & 1 & 0.5 & 97 & 0 & 0.0 & 100 & 1 & 1.0 & -0.97989 \\
L Fibula & 188 & 5 & 2.7 & 94 & 2 & 2.1 & 94 & 3 & 3.2 & -0.46026 \\
R Fibula & 192 & 2 & 1.0 & 96 & 1 & 1.0 & 96 & 1 & 1.0 & - \\
L Os coxa & 192 & 0 & 0.0 & 96 & 0 & 0.0 & 96 & 0 & 0.0 & - \\
R Os coxa & 189 & 2 & 1.1 & 95 & 0 & 0.0 & 94 & 2 & 2.1 & -1.44788 \\
L Ribs & 1725 & 64 & 3.7 & 940 & 33 & 3.5 & 785 & 31 & 3.9 & -0.19285 \\
R Ribs & 1738 & 63 & 3.6 & 925 & 20 & 2.2 & 813 & 43 & 5.3 & -1.38899 \\
Cervical v & 838 & 0 & 0.0 & 424 & 0 & 0.0 & 414 & 0 & 0.0 & - \\
Thoracic v & 1686 & 4 & 0.2 & 876 & 4 & 0.5 & 810 & 0 & 0.0 & 0.659199 \\
Lumbar v & 730 & 10 & 1.4 & 372 & 6 & 1.6 & 358 & 4 & 1.1 & 0.302735 \\
& & & & & & & & & & \\
& & & & & & & &
\end{tabular}

*significant at $0.05 ; * *$ significant at 0.01 
Table 3: Trauma frequencies in the SA white sample ( $\mathrm{n}=200)$. Z-score refers to the Equality of Proportions test (for a 2-sample case) to test for significant differences between the sexes. $\mathrm{Npr}=$ number of bones that were assessed; Naff = number of bones with fractures

\begin{tabular}{llllllllllc}
\hline Bone & \multicolumn{3}{l}{ Both sexes } & \multicolumn{3}{l}{ Males } & \multicolumn{3}{l}{ Females } & Z-score \\
\hline & Npr & Naff $\%$ & Npr & Naff & $\%$ & Npr & Naff & $\%$ & \\
\hline Skull & 191 & 11 & 5.76 & 99 & 8 & 8.1 & 92 & 3 & 3.3 & 1.4287 \\
Mandible & 175 & 4 & 2.3 & 91 & 2 & 2.2 & 84 & 2 & 2.4 & -0.0810 \\
L Scapula & 197 & 2 & 1.0 & 100 & 1 & 1.0 & 97 & 1 & 1.0 & -0.0216 \\
R Scapula & 197 & 4 & 2.0 & 98 & 1 & 1.0 & 99 & 3 & 3.0 & -1.0001 \\
L Clavicle & 156 & 1 & 0.6 & 72 & 0 & 0 & 84 & 1 & 1.2 & -0.9288 \\
R Clavicle & 154 & 7 & 4.5 & 68 & 5 & 7.4 & 86 & 2 & 2.3 & 1.4873 \\
L Humerus & 197 & 3 & 1.5 & 97 & 0 & 0 & 100 & 3 & 3.0 & -1.7190 \\
R Humerus & 197 & 4 & 2.0 & 99 & 1 & 1.0 & 98 & 3 & 3.1 & -1.0206 \\
L Radius & 199 & 4 & 2.0 & 99 & 0 & 0 & 100 & 4 & 4.0 & $-2.0103^{*}$ \\
R Radius & 196 & 14 & 7.1 & 97 & 6 & 6.2 & 99 & 8 & 8.1 & -0.5151 \\
L Ulna & 199 & 3 & 1.5 & 99 & 1 & 1.0 & 100 & 2 & 2.0 & -0.5730 \\
R Ulna & 195 & 2 & 1.0 & 97 & 1 & 1.0 & 98 & 1 & 1.0 & 0.0073 \\
L Femur & 199 & 9 & 4.5 & 99 & 4 & 4.0 & 100 & 5 & 5.0 & -0.3257 \\
R Femur & 200 & 4 & 2.0 & 100 & 0 & 0 & 100 & 4 & 4.0 & $-2.0203^{*}$ \\
L Tibia & 197 & 4 & 2.0 & 98 & 4 & 4.1 & 99 & 0 & 0 & $2.0309^{*}$ \\
R Tibia & 200 & 3 & 1.5 & 100 & 3 & 3.0 & 100 & 0 & 0 & 1.7452 \\
L Fibula & 197 & 5 & 2.5 & 99 & 4 & 4.0 & 98 & 1 & 1.0 & 1.3475 \\
R Fibula & 198 & 5 & 2.5 & 98 & 4 & 4.1 & 100 & 1 & 1.0 & 1.3819 \\
L Os Coxa & 199 & 5 & 2.5 & 99 & 3 & 3.0 & 100 & 2 & 2.0 & 0.4643 \\
R Os Coxa & 199 & 5 & 2.5 & 99 & 5 & 5.1 & 100 & 0 & 0 & $2.2761^{*}$ \\
L Ribs & 2174 & 138 & 6.3 & 1063 & 79 & 7.4 & 1111 & 59 & 5.3 & $2.0278^{*}$ \\
R Ribs & 2161 & 99 & 4.6 & 1059 & 55 & 5.2 & 1102 & 44 & 4.0 & 1.3347 \\
Cervical v & 1306 & 0 & 0 & 657 & 0 & 0 & 649 & 0 & 0 & - \\
Thoracic v & 2309 & 2 & 0.1 & 1171 & 2 & 0.2 & 1138 & 0 & 0 & 1.3947 \\
Lumbar v & 955 & 7 & 0.7 & 477 & 7 & 1.5 & 478 & 0 & 0 & $2.6583^{\star *}$ \\
\hline
\end{tabular}

*significant at $0.05 ;{ }^{* *}$ significant at 0.01 
Table 4: Trauma frequencies in the SA black sample $(\mathrm{n}=200)$. Z-score refers to the Equality of Proportions test (for a 2-sample case) to test for significant differences between the sexes. $\mathrm{Npr}=$ number of bones that were assessed; Naff = number of bones with fractures

\begin{tabular}{lllllllllll}
\hline Bone & \multicolumn{3}{l}{ Both sexes } & \multicolumn{3}{l}{ Males } & \multicolumn{2}{l}{ Females } & Z-score \\
\hline & Npr & Naff & \% & N pr & N aff & $\%$ & N pr & N aff & $\%$ & \\
\hline Skull & 198 & 34 & 17.2 & 100 & 15 & 15.0 & 98 & 19 & 19.4 & -0.8185 \\
Mandible & 173 & 4 & 2.3 & 86 & 2 & 2.3 & 87 & 2 & 2.3 & 0.0117 \\
L Scapula & 192 & 3 & 1.6 & 97 & 0 & 0 & 95 & 3 & 3.2 & -1.764 \\
R Scapula & 191 & 1 & 0.5 & 96 & 1 & 1.0 & 95 & 0 & 0 & 0.99739 \\
L Clavicle & 115 & 6 & 5.2 & 48 & 4 & 8.3 & 67 & 2 & 3.0 & 1.27183 \\
R Clavicle & 120 & 4 & 3.3 & 49 & 1 & 2.0 & 71 & 3 & 4.2 & -0.6553 \\
L Humerus & 200 & 4 & 2.0 & 100 & 2 & 2.0 & 100 & 2 & 2.0 & - \\
R Humerus & 198 & 2 & 1.0 & 99 & 1 & 1.0 & 99 & 1 & 1.0 & - \\
L Radius & 198 & 11 & 5.6 & 100 & 3 & 3.0 & 98 & 8 & 8.2 & -1.5858 \\
R Radius & 198 & 7 & 3.5 & 100 & 3 & 3.0 & 98 & 4 & 4.1 & -0.4121 \\
L Ulna & 197 & 28 & 14.2 & 98 & 14 & 14.3 & 99 & 14 & 14.1 & 0.029 \\
R Ulna & 196 & 16 & 8.2 & 100 & 5 & 5.0 & 96 & 11 & 11.5 & -1.65077 \\
L Femur & 199 & 2 & 1.0 & 100 & 1 & 1.0 & 99 & 1 & 1.0 & -0.0071 \\
R Femur & 199 & 2 & 1.0 & 100 & 1 & 1.0 & 99 & 1 & 1.0 & -0.0071 \\
L Tibia & 196 & 3 & 1.5 & 98 & 2 & 2.0 & 98 & 1 & 1.0 & 0.58182 \\
R Tibia & 198 & 7 & 3.5 & 98 & 6 & 6.1 & 100 & 1 & 1.0 & 1.95145 \\
L Fibula & 197 & 15 & 7.6 & 99 & 9 & 9.1 & 98 & 6 & 6.1 & 0.78544 \\
R Fibula & 197 & 16 & 8.1 & 97 & 9 & 8.2 & 100 & 7 & 7.0 & 0.58525 \\
L Os Coxa & 195 & 1 & 0.5 & 100 & 0 & 0 & 95 & 1 & 1.1 & -1.0286 \\
R Os Coxa & 194 & 3 & 1.5 & 99 & 2 & 2.0 & 95 & 1 & 1.1 & 0.54599 \\
L Ribs & 1983 & 189 & 9.5 & 977 & 147 & 15.0 & 1006 & 42 & 4.2 & $8.24213^{* *}$ \\
R Ribs & 1983 & 141 & 7.1 & 978 & 102 & 10.4 & 1005 & 39 & 3.9 & $5.67315^{* *}$ \\
Cervical v & 1217 & 0 & 0 & 617 & 0 & 0 & 600 & 0 & 0 & - \\
Thoracic v & 2182 & 0 & 0 & 1138 & 0 & 0 & 1044 & 0 & 0 & - \\
Lumbar v & 903 & 0 & 0 & 476 & 0 & 0 & 427 & 0 & 0 & - \\
\hline
\end{tabular}

*significant at $0.05 ; * *$ significant at 0.01 
Table 5 Comparison of trauma frequencies between all three populations (bones of both sides and both sexes combined)

\begin{tabular}{|c|c|c|c|c|c|c|c|c|c|c|c|c|}
\hline \multirow[t]{2}{*}{ Bone } & \multicolumn{3}{|c|}{ Cretes ( C) } & \multicolumn{3}{|c|}{ SA white (SAW) } & \multicolumn{3}{|c|}{ SA black (SAB) } & \multicolumn{3}{|l|}{ z-score } \\
\hline & $\mathrm{Npr}$ & Naff & $\%$ & $\mathrm{Npr}$ & Naff & $\%$ & $\mathrm{Npr}$ & Naff & $\%$ & C-SAW & C-SAB & SAW-SAB \\
\hline Skull & 199 & 1 & 0.5 & 191 & 11 & 5.76 & 198 & 34 & 17.2 & $-3.00502 * *$ & $-5.8571 * *$ & $-3.51821 * *$ \\
\hline Mandible & 197 & 0 & 0 & 175 & 4 & 2.29 & 173 & 4 & 2.3 & $-2.133495 *$ & $-2.1459 *$ & -0.01645 \\
\hline Scapula & 383 & 1 & 0.26 & 394 & 6 & 1.52 & 383 & 4 & 1 & -1.86095 & -1.346 & 0.591565 \\
\hline Clavicle & 365 & 3 & 0.82 & 310 & 8 & 2.58 & 235 & 10 & 4.3 & -1.79845 & $-2.8196 * *$ & -1.08343 \\
\hline Humerus & 388 & 9 & 2.32 & 394 & 7 & 1.78 & 396 & 6 & 1.5 & 0.53622 & 0.82206 & 0.288866 \\
\hline Radius & 385 & 24 & 6.23 & 395 & 18 & 4.56 & 396 & 18 & 4.5 & 1.037303 & 1.04571 & 0.007764 \\
\hline Ulna & 379 & 5 & 1.32 & 394 & 5 & 1.27 & 393 & 44 & 11.2 & 0.061776 & $-5.6269 * *$ & $-5.76261 * *$ \\
\hline Femur & 391 & 25 & 6.39 & 399 & 13 & 3.26 & 398 & 4 & 1.01 & $2.059323 *$ & $4.02214^{* *}$ & $2.201252 *$ \\
\hline Tibia & 393 & 5 & 1.27 & 397 & 7 & 1.76 & 394 & 10 & 2.5 & -0.56412 & -1.2985 & -0.75137 \\
\hline Fibula & 380 & 7 & 1.84 & 395 & 10 & 2.53 & 394 & 31 & 7.9 & -0.65515 & $-3.8788 * *$ & $-3.37667 * *$ \\
\hline Os coxa & 381 & 2 & 0.52 & 398 & 10 & 2.51 & 389 & 4 & 1 & $-2.25175^{*}$ & -0.7942 & 1.574952 \\
\hline Ribs & 3463 & 127 & 3.67 & 4335 & 237 & 5.47 & 3966 & 330 & 8.3 & $-3.74345^{* *}$ & $-8.3272 * *$ & $-5.14796 * *$ \\
\hline Vertebrae & 3254 & 14 & 0.43 & 4570 & 9 & 0.2 & 4302 & 0 & 0 & 1.878723 & $4.30619 * *$ & $2.912184^{* *}$ \\
\hline
\end{tabular}

*significant at $0.05 ; * *$ significant at 0.01 
List of figures:

Fig 1 Example of healed sharp force trauma in a South African black male

Fig 2 Example of surgical trauma in a white male 
